\title{
Keep Hope Alive
}

\author{
Kim Covell
}

Published online: 24 July 2012

(C) Springer Science+Business Media, LLC 2012

I am not a scientist, a doctor or a researcher. I am just an ordinary working mother. So why would I be interested in the DSM or, more specifically, its proposed updates? It's because I am the mother of an extraordinary child who, not too long ago, was diagnosed with one of the mysterious disorders that fills the thousands of pages of that book.

Seemingly overnight, my joyful son with the infectious belly laugh was afraid. He was afraid of everything, anxious, nervous and sometimes, I am convinced, did not even recognize me as his mother. Looking back, I think something in his brain was twisting my facial features, adding to his fear. For months he would cry, alternating between the phrases "I am nervous" and "I am sad." In desperation, we tried medication, which only intensified his distress.

And then he was quiet.

The fear was replaced with emptiness. His cheerful giggle that filled the house just a few months before was gone. Questions were answered with a blank stare.

In an effort to create an educational program appropriate for a radically new set of needs, my son was evaluated at the Yale Child Study Center. My account of the preceding 2 years and documentary video caught the attention of the clinicians. All evidence pointed to Childhood Disintegrative
Disorder. I had never heard of CDD and so it was not until returned home and began to read about it online that the devastating nature of the disorder sunk in. My hopes and dreams for my son evaporated.

Hope, gladly, has returned. Besides the obvious wish for my son to have a full and happy life, my hope is for answers. It's the unknown that is difficult. From a clinical perspective my son has autism, but it's much more. The question is how he got there. Having been exposed to the breadth of the spectrum through autism programming offered by a nonprofit I founded, I can easily detect subtle differences between those diagnosed with classic autism and my own son.

The proposed change in the DSM-V that would subsume CDD under the broader autism diagnosis would end any hope for an answer to what causes the disorder. There is sufficient evidence that CDD has a distinct cause separate from that of autism and so closing the door on a CDD diagnosis would threaten to halt research that could provide answers to both CDD and autism. Given the developmental devastation wreaked by CDD and the ensuing outcomes, it is imperative that that committee recognize CDD as a separate diagnosis. To do otherwise would imperil hope.

Kim Covell is the parent of a child diagnosed in 2009 with Childhood Disintegrative Disorder

K. Covell $(\square)$

Water Mill, NY, USA

e-mail: Kcm11976@optonline.net 